\title{
Synthesis of 2-(4-((6-bromo-3-nitroquinolin-4-yl)amino) phenyl)-2-methylpropanenitrile
}

\author{
Fei Lei ${ }^{1}$, Yuanbiao $\mathrm{Tu}^{1}$, Min Wang ${ }^{1}$, WenHui Wang ${ }^{1}$, Qidong Tang ${ }^{{ }^{\star}}{ }^{\star}$, \\ Shan $\mathrm{Xu}^{1,{ }^{1} \mathrm{~b}}$ \\ ${ }^{1}$ School of Pharmacy, Jiangxi Science \& Technology Normal University, Nanchang 330013, China \\ *atangqidong@126.com, Shanxu9891@126.com
}

Keywords: PI3K/mTOR inhibitors,6-bromoquinolin-4-ol,Synthesis

\begin{abstract}
.2-(4-((6-bromo-3-nitroquinolin-4-yl)amino)phenyl)-2-methylpropanenitril(7) is an important intermediate in many PI3K/mTOR inhibitors. The compound 5 was synthesized from 6-bromoquinolin-4-ol (1) and 2-(4-nitrophenyl)acetonitrile(4) through five steps including nitration, chlorination, alkylation, reduction and substitution. These structures were confirmed by ${ }^{1} \mathrm{HNMR}$ and MS spectrum. The synthetic method of 7 was optimized and can be used to synthesize the derivatives of NVP-BEZ235.
\end{abstract}

\section{Introduction}

Tumor molecular targeted therapy has become more and more popular in cancer treatment. The PI3K-Akt-mTOR signaling pathway was composed of Phosphoinositide 3-kinase,PAKT/PKB and mTOR. This pathway controled many important biological processes in the development of tumor ${ }^{[1]}$. Currently, there are many kinds of inhibitors. PI3K inhibitors bearing quinoline is a kind of important compound to treat cancer. Novartis has developed a series of quinoline PI3K/mTOR inhibitors(Fig.1)and most of them showed extent antitumor activite. The compound NVP-BBD130 is one of the typical representatives ${ }^{[2]}$. It acts on PI3K, PI3K beta, gamma, delta and mTOR. NVP-BBD130 was optimized to get NVP - BEZ235. It also works on PI3K/mTOR ${ }^{[3-4]}$, and it can obviously reduce the mTOR activated kinase p70S6K phosphorylation level ${ }^{[5]}$. The associated application of NVP-BEZ235 in solid tumor and some of the blood system tumor was reported, including combination with chemotherapy drugs, combination with other molecular targeted drugs as well as combination therapy with radiotherapy and so on ${ }^{[6-10]}$.

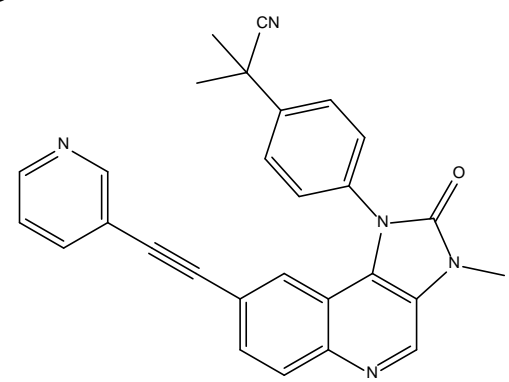

NVP-BBD130

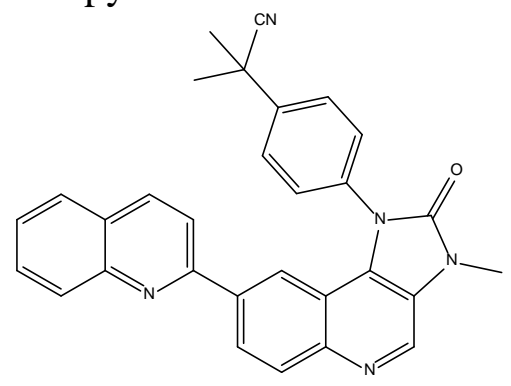

NVP-BEZ235

Fig.1 Structures of NVP-BBD130 and the representative compounds in study

2- (4- (( 6-bromo-3-nitroquinolin-4-yl)amino) phenyl) -2-methylpropanenitrile is a key intermediate for the synthesis of quinoline inhibitors. Compound 7 was synthesized from 6-bromo-4-chloro-3-nitroquinoline(3) and 2-(4-aminophenyl)-2 -methylpropanenitrile(6)(Fig.2). In this paper, we summarized and optimized the synthetic methods of compound $\mathbf{1}$. 


\section{Materials and methods}

All melting points were obtained on a Büchi Melting Point B-540 apparatus (Büchi Labortechnik, Flawil, Switzerland) and were uncorrected. NMR spectra were performed using Bruker $400 \mathrm{MHz}$ spectrometers (Bruker Bioscience, Billerica, MA, USA) with TMS as an internal standard. Mass spectra (MS) were taken in ESI mode on Agilent 1100 LC-MS (Agilent, Palo Alto, CA, USA). All the materials were obtained from commercial suppliers and used without purification, unless otherwise specified. Yields were not optimized. TLC analysis was carried out on silica gel plates GF254 (Qindao Haiyang Chemical, China).

\section{Synthesis of compounds}

The structures and the synthetic route were shown in Scheme 1.

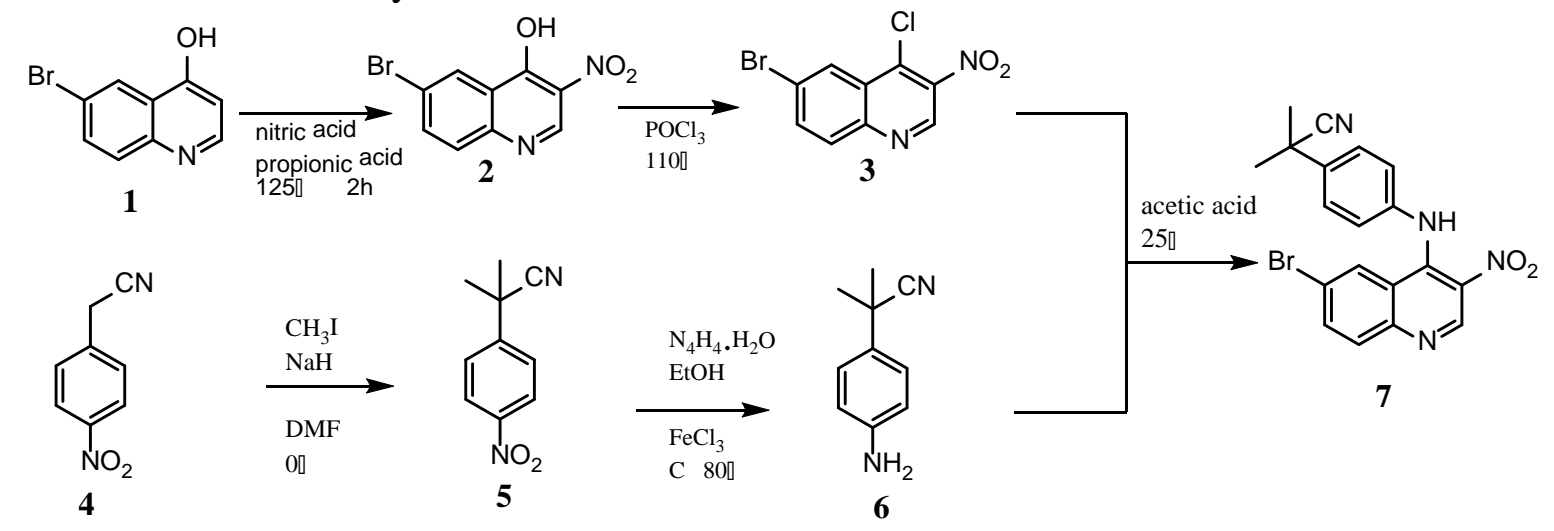

\section{Preparation for 6-bromo-3-nitroquinolin-4-ol (2)}

The solution of compound $15 \mathrm{~g}$ ( $22 \mathrm{mmol}$ ) in $250 \mathrm{~mL}$ propionic acid was stirred and the mixture of $12 \mathrm{~mL}$ nitric acid and $13 \mathrm{~mL}$ propionic acid was added dropwise for $1 \mathrm{~h}$ at $\mathrm{rt}$. Raise the temperature to $125^{\circ} \mathrm{C}$. Then the mixture was reacted for $2 \mathrm{~h}$ and filtered by solid. The solid was washed with saturated $\mathrm{NaHCO}_{3}$ solution for $1 \mathrm{~h}$ at $0^{\circ} \mathrm{C}$,filtration,the filte cake was dried to obtain a yellow powdery solid (3.54g 59.03\%) ${ }^{[3]}$. ESI-MS m/z: 268.9(M-H)

Preparation for 6-bromo-4-chloro-3-nitroquinoline (3)

The solution of compound $23.54 \mathrm{~g}(13 \mathrm{mmol})$ in $100 \mathrm{~mL} \mathrm{POCl}_{3}$ was stirred and 4 drops DMF was added into the solution. Then the mixture was reacted for $2 \mathrm{~h}$ at $110^{\circ} \mathrm{C}$.The solution was concentrated under reduced pressure to afford a yellow solid. The solid was washed with saturated $\mathrm{NaHCO}_{3}$ solution for $1 \mathrm{~h}$ at $0^{\circ} \mathrm{C}$, filtration,the filte cake was dried to obtain a milk white solid(3.22g 85\%). ESI-MS m/z: 287.5[M - H] $]^{-}$

Preparation for 2-methyl-2-(4-nitrophenyl)propanenitrile (5) 2-(4-nitrophenyl)acetonitrile (4) $10 \mathrm{~g}(61 \mathrm{mmol})$ was first dissolved in $260 \mathrm{~mL} \mathrm{DMF}, 60 \% \mathrm{NaH} 9.76 \mathrm{~g}(244 \mathrm{mmol})$ was added into solution and was stirred for $1 \mathrm{~h}$ at $0^{\circ} \mathrm{C}$. Then, the mixture $\mathrm{CH}_{3} \mathrm{I} 21.66 \mathrm{~g}(153 \mathrm{mmol})$ of $10 \mathrm{~mL} \mathrm{DMF}$ was added dropwise, the mixture solution was reacted for $3 \mathrm{~h}$ and filter by filtrate.The filtrate mixed with ice water was stirred for 1h,precipitation, filtration by green solid(10.58 90.21\%). ESI-MS $\mathrm{m} / \mathrm{z}: 190.1[\mathrm{M}-\mathrm{H}]^{-}$

Preparation for 2-(4-aminophenyl)-2-methylpropanenitrile (6)

A mixture of compound $510.58 \mathrm{~g}(55.6 \mathrm{~m} \mathrm{~mol}), 500 \mathrm{~mL}$ EtOH was stirred for $0.5 \mathrm{~h}$. $\mathrm{FeCl}_{3} 3.0 \mathrm{~g}$, activated carbon $10.03 \mathrm{~g}$ were added into the solution and raise the temperature to $80^{\circ} \mathrm{C}$. $80 \%$ hydrazine hydrate $34.75 \mathrm{~g}(556 \mathrm{mmol})$ was added dropwise and refluxed for $1 \mathrm{~h}$. The mixture was then filtered, washed with EtOH.The filtrate was died by anhydrous sodium sulfate for 1 day ,filtration,the filtrate was concentrated under reduced pressure to afford a yellow oil(6.71g 74.84\%). ESI-MS m/z:161.4 [M - H] $]^{+}$ 
7)

Preparationfor2-(4-((6-bromo-3-nitroquinolin-4-yl)amino)phenyl)-2-Methylpropanenitrile(

The mixture of compound $33.22 \mathrm{~g}(11.2 \mathrm{mmol}), 100 \mathrm{~mL}$ acetic acid was stirred for $1 \mathrm{~h}$ at room temperature.Compound $62.44 \mathrm{~g}(12.3 \mathrm{mmol})$ was added dropwise into the solution.The mixture was refluxed for $1 \mathrm{~h}$,filtration,filter cake was dried to obtain yellow solid(2.3g 50\%).ESI-MS m/z: 411.0[M - H] ${ }^{-1}{ }^{1} \mathrm{H}$ NMR(400 MHz, DMSO) $\delta 9.00(\mathrm{~s}, 1 \mathrm{H}), 8.64$ (s, 1H), $7.91(\mathrm{~s}, 1 \mathrm{H}), 7.85$ (d, 1H), 7.72 (d, 1H), 7.38 (d, 2H), 7.02 (d, 2H), 1.63 (s, 6H).

\section{Conclusions}

In conclusion,one novel compound 7 was synthesized from 6-bromoquinolin-4-ol and 2-(4-nitrophenyl)acetonitrile through five steps. The synthetic routecan be used to synthesize 2-(4-((6-bromo-3-nitroquinolin-4-yl)amino)phenyl)-2-methylpropane-nitrie

\section{Acknowledgments}

We gratefully acknowledge the generous support provided by The National Natural Science Funds (No.80140357) , Project supported by the Natural Science Foundation of Jiangxi Province (No. 20142BAB215020) and Program of Key Laboratory of Drug Design and Optimization, Jiangxi Science \& Technology Normal University (300098010306)

\section{References}

[1] Wee S, Lengauer C, Wiederschain D. Class I A phosphoinositide 3-kinase isoforms and human tumorigenesis:implications for cancer discovery and development, J. Curr Opin Oncol. 20 (2008) 77-82

[2] Marone R, Erhart D, Mertz AC, et al. Targeting Melanoma with Dual Phosphoinositide 3-Kinase/Mammalian Target of Rapamycin Inhibitors , J. Mol. Cancer Res.,7 (2009) 601-613.

[3] Violeta Serra, Ben Markman, Maurizio Scaltriti, et al. NVP-BEZ235, a dual PI3K/mTOR inhibitor, prevents PI3K signaling and inhibits the growth of cancer cells with activating PI3K mutations, J. Cancer Res . 8 (2008) 8023-8025.

[4] Kima, Parks. LeeJE,et al. The dual PI3K and mTOR inhibitor NVP-BEZ235 oxhibits anti-proliferative activity and overcomes bortezomib resistance in mautle cell lymphoma cells, J. Leak Res. 36(2012) 912-920.

[5] Serra V, Markman B, Scaltriti M, et al. NVP-BEZ235, a dual PI3K/mTOR inhibitor, prevents PI3K signaling and inhibits the growth of cancer cells with activating PI3K mutations, J. Cancer Res. 68 (2008) 8022-8030.

[6] Maria C. Manara, Giordano Nicocetti, Diana Zambelli, Selena Ventura, Clara Guerzoni, Lorena Landuzzi, Pier-Luigi Lollini, Saveur-Michel Maira, Carlos Garcia-Echeverria, Mario Mercuri, Piero Picci, and Katia Scotlandi. NVP-BEZ235 as a new therapentic option for sarcomas, J. Clin Cancer Res. 16(2010,):531-535.

[7] Kima, Parks. LeeJE,et al. The dual PI3K and mTOR inhibitor NVP-BEZ235 oxhibits anti-proliferative activity and overcomes bortezomib resistance in mautle cell lymphoma cells, J. Leak Res. 36 (2012) 912-920.

[8] Roulin D, Waselle L, Dormond-Meuwly A, et al. Targeting renal cell carcinoma with NVP-BEZ235, a dual PI3K/mTOR inhibitor, in combination with sorafenib , J. Mol Cancer. 10 (2011) 90-95.

[9] Awasthi N, Yen PL, Schwarz MA, et al. The efficacy of a novel, dual PI3K/mTOR inhibitor 
NVP-BEZ235 to enhance chemotherapy and antiangiogenic response in pancreatic cancer, J. Cell Biochem. 113 (2012) 784-791.

[10] Manara MC, Nicoletti G, Zambelli D, et al. NVP-BEZ235 as a new therapeutic option for sarcomas , J. Clin Cancer Res. 16 (2010) 530-540. 